\title{
Abundance estimates of Southern Hemisphere Breeding Stock 'D' humpback whales from aerial and land-based surveys off Shark Bay, Western Australia, 2008
}

\author{
Sharon L. Hedley*, John L. Bannister ${ }^{+}$And Rebecca A. DunloP ${ }^{\#}$ \\ Contactemail: sharon@countingwhales.co.uk
}

\begin{abstract}
Single platform aerial line transect and land-based surveys of Southern Hemisphere Breeding Stock 'D' humpback whales Megaptera novaeangliae were undertaken off Shark Bay, Western Australia to provide absolute abundance estimates of animals migrating northward along the western Australian coast. The aerial survey flew a total of 28 flights, of which 26 were completed successfully, from 24 June-19 August 2008 . The landbased survey was undertaken from Cape Inscription, Dirk Hartog Island, Shark Bay, during the expected peak of the whales' northward migration, from 8-20 July. During the first week of the land-based survey, some double count effort was undertaken to provide information on the numbers of pods missed from the land station. The assumed period of northward migration was 2 June-7 September. Estimated abundance of northwardmigrating whales during that time is 34,290 (95\% CI: $(27,340-53,350))$, representing an annual rate of increase of $12.9 \%(\mathrm{CV}=0.20)$ since an estimate of 11,500 in 1999. This estimate is based on an estimate of relative abundance of surface-available whales of $10,840(8,640-16,860)$, and an estimated $g(0)$ of 0.32 . There were considerable practical difficulties encountered during the land-based survey which reduced the effectiveness of the dual-survey approach for estimating $g(0)$ for the aerial survey. Furthermore only about $15 \%$ of whales were estimated to be within the visual range of the land-based station. Alternative approaches for estimating $g(0)$ from these data are therefore also presented, resulting in considerably higher estimates of around 0.6-0.7, and yielding a conservative abundance estimate of 17,810 (14,210-27,720).
\end{abstract}

KEYWORDS: HUMPBACK WHALE; SOUTHERN HEMISPHERE; SURVEY-AERIAL; SURVEY-SHORE-BASED; MIGRATION; AUSTRALIA

\section{INTRODUCTION}

Following increasing reports of humpback whale (Megaptera novaeangliae) sightings in winter off the western Australian coast in the early-mid 1970s, aerial surveys of humpback whales during their northward migration were undertaken from Carnarvon, Western Australia (WA) in an area off Shark Bay where aerial spotter and other data from whaling operations were available for the last year of humpback whaling, 1963. Results of those surveys to 1988 (Bannister et al., 1991) demonstrated that significantly more whales were seen in the area in the 1980s than in 1963. Further surveys, in 1991 and 1994, demonstrated an annual increase rate of $10.15 \pm 4.6 \%$ to 1994 (see Bannister and Hedley, 2001). In comparison to the estimated population size of 568 at the end of 1963 (Bannister, 1964), the population size in 1994 was calculated to be some 4,000-5,000 animals (Bannister, 1995).

The 1994 survey results showed that to detect a significant difference in population in future years, at an annual increase of $10 \%$, an interval of three years would be required between surveys, leading to a proposed further survey in 1997. Given funding constraints, that survey took place in 1999, its aim being to provide an estimate of absolute abundance. This aim was more ambitious than for its predecessors, from which only a relative index had been obtained. The survey was planned to cover as much of the northern migration period as possible, with flights every other day over a two month period, mid June-mid August. Given the prevailing generally poor weather conditions, only 18 of the 30 planned flights could be flown, of which only 15 were completed.
Nevertheless allowing for animals missed while submerged, 1999 population size was estimated as $8,200-13,600$ (Bannister and Hedley, 2001).

Given the disappointing coverage, a further survey was planned to take place as soon as possible over the same period and area, but to include an additional land-based component. That survey took place in 2005 ; the results are reported in Paxton et al. (2011). Unfortunately, although the 2005 survey had been designed with the aim of improving on earlier surveys (which were only able to apply ad hoc corrections to adjust for uncertain trackline detection), lastminute logistical changes to the land-based survey in 2005 reduced its effectiveness. In particular, the location of the land-based survey had to be moved northward to a location where, in the event, whales often exhibited 'milling' behaviour rather than directional swimming more typical of migrating animals, and to where the offshore distribution of whales extended far beyond the visual range of the landbased observers.

Given rather equivocal results from the 2005 survey, improvements to the design of the 2008 survey were planned as follows:

(1) The aerial survey component was expanded in area to extend offshore coverage (following some experimental work in 2007 to determine the most appropriate survey area).

(2) Aerial survey data were collected using a direct data acquisition system.

(3) The land-based component of the survey was expanded to include some double-platform independent observer 
counts, and thus allow estimation of a correction factor for whales missed by the land-based observers.

(4) The location of the land-based platforms was at Cape Inscription, Dirk Hartog Island, Shark Bay. From previous surveys, it was expected that whales passing this location would be more identifiable as 'northwardmigrating' and furthermore, that they would pass closer to the shore at this latitude.

This report details the analysis of data from the 2008 survey, the aerial component of which took place from 24 June-19 August, with the land-based component from 8-20 July.

\section{FIELD METHODS AND DATA}

\section{Aerial survey}

In 1999 , most sightings were made within about $30 \mathrm{~km}$ of the eastern edge of the survey area - an area of coastline delineated by the western coastlines of Bernier, Dorre and Dirk Hartog Islands (see Bannister and Hedley, 2001), although the transects had extended out to about $56 \mathrm{~km}$ from those islands. In 2005, the sightings were spread more evenly (in relation to distance offshore) throughout the survey area (Paxton et al., 2011). A small set of flights in 2007 over the same area but with two legs extending $92 \mathrm{~km}$ offshore (to $112^{\circ} \mathrm{E}$ ) suggested that humpback whales might be found out to $65 \mathrm{~km}$ offshore (i.e. to about $112^{\circ} 25^{\prime} \mathrm{E}$ ) but with only a very few further out. The 2008 flight path was therefore planned to cover an area reduced in latitudinal coverage from that surveyed previously, approximately $55 \mathrm{~km} \times 75 \mathrm{~km}$ immediately west of Dorre and Dirk Hartog Islands on the western boundary of Shark Bay. The reduction in latitudinal effort allowed for two extended transect legs of about $70 \mathrm{~km}$ length to be flown to provide information on the possible distribution of animals further offshore. These were located off the north of Dirk Hartog Island. In addition, on seven flights when the land-based survey was operating, short legs of about $20 \mathrm{~km}$ were flown at the latitude of Cape Inscription. The survey area and a typical flight path are shown in Fig. 1. The approximate length of the two most northerly and two most southerly east-west transects was $45-50 \mathrm{~km}$. The survey area covered a region of approximately $6,570 \mathrm{~km}^{2}$.

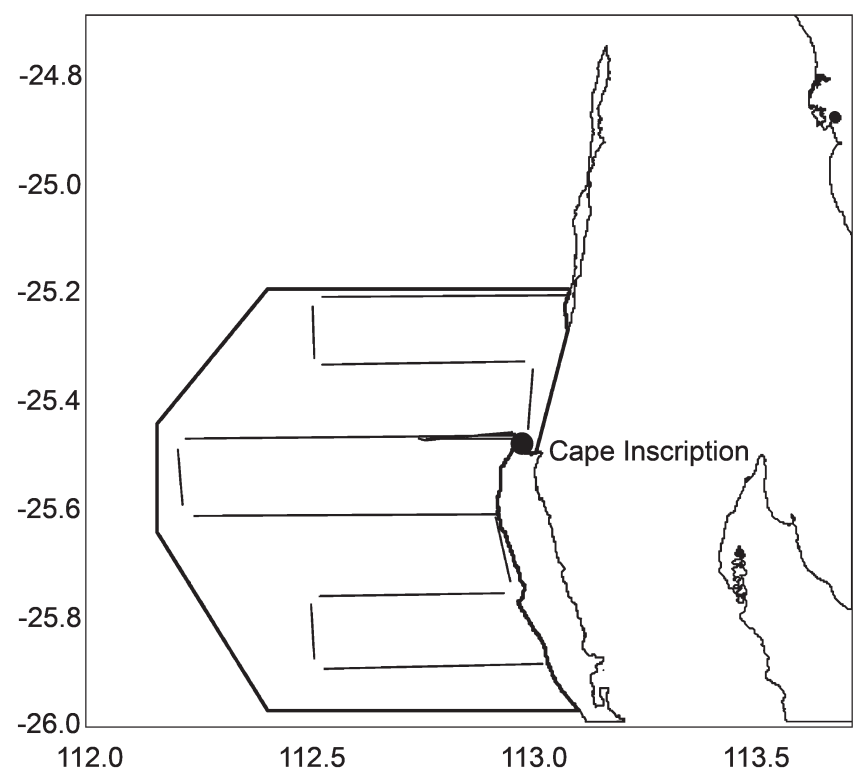

Fig. 1. Survey area for aerial survey, and typical flight path. (Flight 8 on 10 July shown)
As in 1999 and 2005, the 2008 survey flights were undertaken from a high-wing, twin-engine aircraft, mainly a Partenavia P68B (fitted with bubble windows), under charter from TropicAir Services Pty Ltd, flying out of Carnarvon, WA. On four flights, a Cessna 337 (with flat windows) was chartered from Norwest Air Work Pty Ltd, based in Exmouth, WA. On all flights, a GPS and on-board computer system were available to plot waypoints (as on previous surveys) and to log data (such as time, position and altitude); in addition, in 2008, Cyclopes software (Kniest, University of Newcastle, Australia) was employed to map the flight path. Separately for each side of the aircraft, the two observers recorded various weather covariates, including: Glare strength (a factor with four levels); Glare angle; Beaufort sea state; Wind strength (in knots); Wind direction; Percentage cloud cover; and Sightability, a subjective overall assessment of the sighting conditions (a factor with four levels). Observers used a clinometer (industry standard Suunto PM-5/360PC) and an angleboard to measure declination and horizontal angles to sightings. For each sighting, observers made every effort to record pod size and swimming direction. All sighting details were recorded on a Sony digital recorder for post-flight data entry. A total of four observers participated in the survey, with their levels of participation ranging from flying 24 of the 28 flights $(85 \%)$ down to $7(25 \%)$.

Of the 28 flights flown, 26 of were successfully completed and included in the analysis. The first three flights (on 24, 26 and 29 June) were flown in a northerly direction; the remainder were flown in a southerly direction. Because of glare, usually the latter is preferable for surveys in this location; historically (when transects were closer together) such a strategy has also been used in order to minimise the risk of double-counting animals (flying was in the opposite direction to the whales' migration path).

Table 1 details the date, total transect length and number of sightings for each flight. 'NM' sightings are those pods recorded with a northward swimming (migration) direction. $\mathrm{NM}+$ sightings additionally include some pods of undetermined direction, randomly allocated to be travelling north in proportion to the sightings of known direction on a given day which were travelling northwards.

\section{Land-based survey}

Sighting survey

The land-based survey took place from Cape Inscription, on the northern end of Dirk Hartog Island - a rugged and exposed area with virtually no facilities at the site. The observation site was low, with the highest accessible point being just $25.5 \mathrm{~m}$ above sea level.

Survey effort was scheduled for 9 hours each day from 820 July; 7 full days were completed together with three partial days (of 6, 7 and 2.5 hours respectively), with no effort possible on 11 and 20 July. During the first survey week (8-13 July), five hours of double-platform (independent observer) data were also collected on each day with suitable survey conditions ( 25 hours in total), with four observers assigned to each of the two teams ('Car' and 'Bush'). During the second week, reduced personnel resulted in it only being feasible to conduct single-platform survey; these observations were augmented by 'focal follows' (i.e. each surfacing of a detected pod recorded until out of visible range) without disruption to the sightings survey.

Whales were spotted by the observers and sightings were input directly into a notebook computer running Cyclopes (software specifically designed for the tracking of marine 
Table 1

Summary of aerial surveys. Flights marked with an asterisk were aborted and their data excluded from the analysis. Numbers in parentheses are the numbers of pods/whales after left-truncation of perpendicular distances at $260 \mathrm{~m}$.

\begin{tabular}{|c|c|c|c|c|c|c|c|c|c|c|c|}
\hline \multirow{2}{*}{$\frac{\text { Flight }}{1}$} & \multirow{2}{*}{$\begin{array}{c}\text { Aircraft } \\
\text { Partnv }\end{array}$} & \multirow{2}{*}{$\begin{array}{c}\text { Date } \\
24 / 06 / 08\end{array}$} & \multirow{2}{*}{$\begin{array}{c}\text { Effort }(\mathrm{km}) \\
540\end{array}$} & \multicolumn{2}{|c|}{$\begin{array}{c}\text { NM pods } \\
\text { (after left-truncation) }\end{array}$} & \multicolumn{2}{|c|}{$\begin{array}{c}\text { NM whales } \\
\text { (after left- truncation) }\end{array}$} & \multicolumn{2}{|c|}{$\begin{array}{c}\mathrm{NM}+\text { pods } \\
\text { (after left-truncation) }\end{array}$} & \multicolumn{2}{|c|}{$\begin{array}{c}\mathrm{NM}+\text { whales } \\
\text { (after left- truncation) }\end{array}$} \\
\hline & & & & 12 & (12) & 26 & (26) & 17 & (17) & 33 & (33) \\
\hline 3 & Partnv & $29 / 06 / 08$ & 530 & 8 & (5) & 20 & (13) & 8 & (5) & 20 & (13) \\
\hline 4 & Partnv & $02 / 07 / 08$ & 570 & 43 & (40) & 71 & (66) & 57 & $(54)$ & 92 & (87) \\
\hline 5 & Partnv & $03 / 07 / 08$ & 470 & 20 & (19) & 39 & (37) & 28 & (27) & 48 & (46) \\
\hline 6 & Partnv & 08/07/08 & 540 & 29 & (28) & 55 & (53) & 35 & (34) & 67 & (65) \\
\hline 8 & Partnv & $10 / 07 / 08$ & 510 & 53 & (50) & 83 & (78) & 67 & (63) & 100 & (94) \\
\hline 9 & Cessna & $13 / 07 / 08$ & 500 & 30 & (30) & 66 & (66) & 42 & (41) & 84 & $(82)$ \\
\hline 10 & Cessna & $14 / 07 / 08$ & 570 & 46 & (46) & 68 & (68) & 54 & (54) & 77 & (77) \\
\hline 11 & Partnv & $16 / 07 / 08$ & 580 & 21 & (20) & 35 & (33) & 78 & (76) & 115 & (112) \\
\hline 12 & Cessna & $17 / 07 / 08$ & 580 & 15 & (14) & 32 & (31) & 32 & (30) & 55 & (51) \\
\hline 13 & Partnv & $22 / 07 / 08$ & 480 & 29 & (25) & 60 & (49) & 68 & (62) & 115 & (101) \\
\hline 14 & Partnv & $23 / 07 / 08$ & 480 & 37 & (32) & 70 & (59) & 56 & (51) & 95 & (84) \\
\hline $15^{*}$ & Partnv & $24 / 07 / 08$ & 190 & 7 & (6) & 9 & (7) & 11 & (10) & 13 & (11) \\
\hline 17 & Partnv & $02 / 08 / 08$ & 490 & 15 & (12) & 25 & (20) & 37 & (34) & 52 & (47) \\
\hline 18 & Partnv & $06 / 08 / 08$ & 440 & 15 & (15) & 28 & (28) & 23 & (23) & 36 & (36) \\
\hline 19 & Partnv & $08 / 08 / 08$ & 460 & 7 & (7) & 13 & (13) & 14 & (14) & 23 & (23) \\
\hline 20 & Partnv & 09/08/08 & 470 & 15 & (13) & 21 & (19) & 27 & (24) & 38 & (35) \\
\hline 21 & Partnv & $10 / 08 / 08$ & 470 & 23 & (21) & 43 & (41) & 28 & (26) & 48 & (46) \\
\hline 22 & Partnv & $12 / 08 / 08$ & 480 & 12 & (12) & 16 & (16) & 20 & (19) & 26 & (25) \\
\hline 23 & Partnv & $13 / 08 / 08$ & 480 & 17 & (16) & 28 & (26) & 26 & (25) & 38 & (36) \\
\hline 24 & Cessna & $14 / 08 / 08$ & 440 & 5 & (5) & 8 & (8) & 8 & (8) & 12 & (12) \\
\hline 25 & Partnv & $15 / 08 / 08$ & 400 & 12 & (12) & 21 & (21) & 23 & (23) & 35 & (35) \\
\hline 26 & Partnv & $16 / 08 / 08$ & 470 & 16 & (16) & 24 & (24) & 26 & (26) & 35 & (35) \\
\hline $27^{*}$ & Partnv & $18 / 08 / 08$ & 190 & 4 & (4) & 7 & (7) & 8 & (8) & 14 & (14) \\
\hline 28 & Partnv & $19 / 08 / 08$ & 470 & 8 & (8) & 11 & (11) & 12 & (12) & 15 & (15) \\
\hline Total & & & 13,220 & 571 & $(536)$ & 1,008 & (939) & 920 & $(876)$ & 1,469 & $(1,387)$ \\
\hline
\end{tabular}

mammals). A theodolite, connected directly to the notebook computer, was also used to measure the positions of passing groups of whales in Cyclopes. One observer operated the theodolite, while another operated the computer. When a sighting was made, the theodolite operator pointed the theodolite at the surfacing pod and with the push of a button, vertical and horizontal bearings were transmitted to, and recorded directly in, Cyclopes. The position of the pod was calculated correcting for tides, curvature of the Earth and refraction, and was plotted on a map of the area. The computer operator added data on pod composition, behaviour and direction of travel, when these could be determined. Cyclopes was thus able to compute pod speed, course and distance from any reference point. For each pod sighted the following information was also recorded using Cyclopes: time (to the nearest second); unique pod identifier (A, B, C, etc.); species confirmation; calf presence; and cue, plus other relevant information such as whether or not the group went into or came from the Shark Bay area to the east of the islands. Whilst perpendicular distance offshore was rarely observed, it was calculable for pods with at least one fix either side of the 'abeam' line from the land-based platform.

The other two observers were 'spotters' who used naked eye or $7 \times 50$ binoculars to sight whales. The spotters were allocated adjacent sectors of the ocean to scan to spread sighting effort as much as possible. Each land-based team attempted to record the behaviour and all surfacings of every sighted group to increase chances of matching between the two land-based teams and the aerial survey. Inevitably however, this was not possible during periods of high densities of whales. Pods further offshore had an increased risk of being 'lost', only sighted once, or being confused with other pods at a similar bearing. Spotter observations were entered as 'additional observations'. The information above was entered for each 'additional observation' and the position was calculated from the bearing and reticule readings taken from the binoculars. Priority for theodolite fixes was given to new pods, after which, theodolite effort was spread as evenly as possible among the pods being tracked in the study site. Pods only sighted once or a small number of times in which group composition could not be accurately determined were counted as 1 animal (unless more than one animal had been spotted). For the double-platform data, an assessment of duplicate status was also recorded.

Weather conditions were recorded hourly and at the beginning and end of each day. Data recorded included sea state, swell height and direction, wind speed and direction, cloud cover (in oktas), glare (degrees of view obscured by glare) and other factors affecting visibility (e.g. smoke, haze, squalls).

Post data collection, all Cyclopes files were reviewed by the (primarily volunteer) researchers each evening and then, for consistency, by an experienced researcher (RAD), who has carried out the same type of work on previous land-based humpback whale surveys off the east coast of Australia.

In the event, a large proportion of the whales migrated past Cape Inscription at considerable distances from the shore, resulting not only in a high proportion of whales being missed, but also in difficulties obtaining theodolite fixes required for tracking of pods and accurate distance estimation. Beyond about $8 \mathrm{~km}$, whales were sighted 'on the horizon'; thus recorded distances $>8 \mathrm{~km}$ could not be considered reliable. The researchers recommended exclusion of all sightings beyond $12 \mathrm{~km}$ as there was no accuracy in these measurements.

The matching process (undertaken by RAD) was severely hampered by the distance inaccuracies, but is assumed to 
Table 2

Summary of land-based survey effort and humpback whale pod sightings. Sightings shown for NM and NM+ pods.

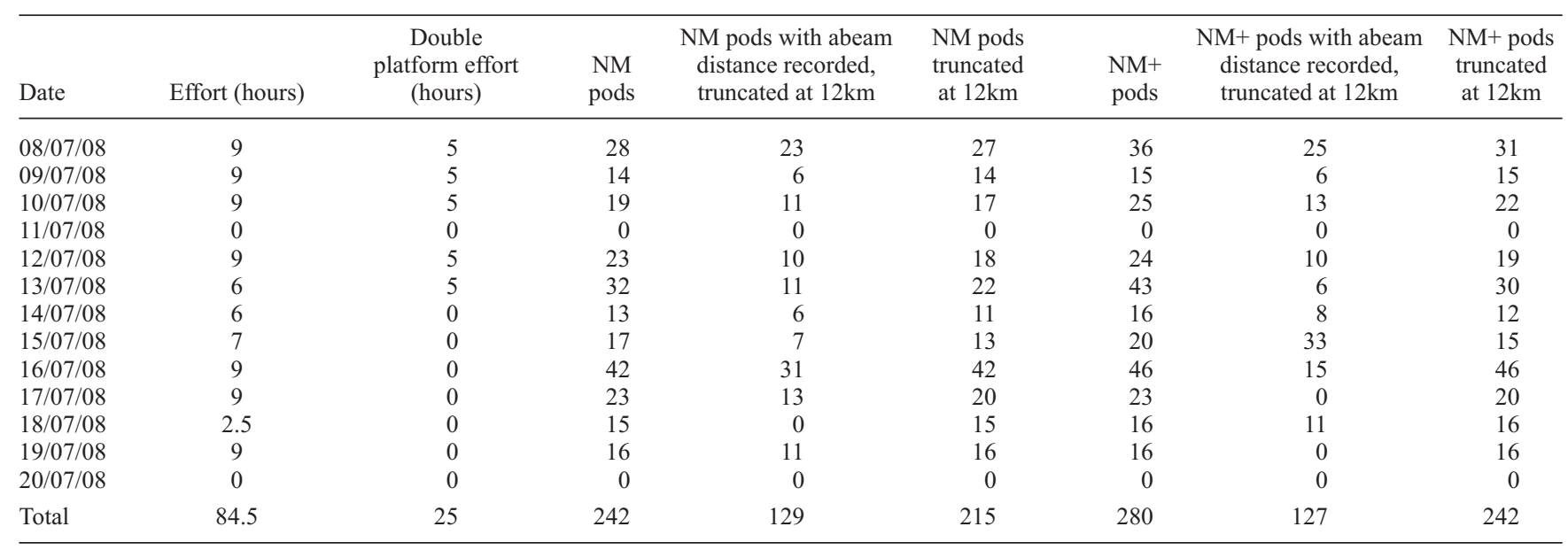

have been completed without error in this analysis (i.e. no account is taken of incorrect duplicate identification). A summary of the land-based survey data is shown in Table 2. The number of NM and NM+ pods sighted is given, together with two further datasets: (1) the number of sightings after truncation at $12 \mathrm{~km}$ offshore (and excluding pods for which no offshore distance was available; and (2) the number of sightings after truncation at $12 \mathrm{~km}$ offshore (and including those pods with no offshore distance).

\section{Focal follows}

In addition to the survey data, a total of 22 focal follows were conducted during the land-based survey, primarily during the second week of the survey. During single platform survey, the focal follow team tracked randomly-selected pods of a range of sizes and composition (singletons, mother and calf groups and multiple adult groups) using a theodolite linked to Cyclopes; an additional observer (with binoculars) aided in keeping track of the group. The minimum time for a focal follow was 20 minutes (which encompassed at least three surface intervals and three deep dives). Surface intervals included shallow dives ('breathing dives') in which the animals disappear for a matter of seconds (usually no longer than 1 minute) before returning to the surface to breathe. These were differentiated from 'deep dives' in which the animals disappear for a number of minutes. For each surfacing of the followed pod, the length of surface interval, mean travel speed during the surface interval and number of blows/breaches and surface-active behaviours (all surface behaviours such as breaches, pectoral slaps, tail slaps and unidentified surface behaviours) per whale per minute of surface time were estimated. For each deep dive, the dive time and mean travel speed during the dive were also estimated. From these data, the mean dive time, surface interval, blow rate, breach rate, surface-active rate and speed of travel were calculated for each pod followed. Focally followed pods were limited to those considered to be travelling north.

\section{ANALYSIS METHODS}

\section{Overview}

The survey objective was to estimate the absolute abundance of northward-migrating humpback whales off Shark Bay. The aim of the aerial survey component was to estimate the number of whale pods seen on a given flight. This number would then require a correction so that it corresponded to the number of pods passing through the area during a given time, say, per day. Such a correction factor would depend on the whales' speed of travel during their northward migration. Without further adjustment, the number of pods per day would be an underestimate of the true number, since uncorrected estimates only estimate the number of whales at the surface and thus those that are available to be seen. In addition to this 'availability' bias, not all whales at the surface are detected, leading to so-called 'perception' bias (Marsh and Sinclair, 1989).

The aim of the land-based survey component was threefold: (1) to provide an estimate of absolute abundance of northward-migrating humpback whale pods during the two weeks of the aerial survey (and thus allow calibration of the corresponding aerial estimates); (2) using the focal follow data, to provide estimates of whale migration speed; and (3) to provide estimates of mean pod sizes (since it was expected that these would be underestimated from the aerial survey).

Combining the results from the two components, estimates of the absolute number of northward-migrating whales passing through the survey area for each day of the aerial survey may be obtained. Fitting a model to these estimates (to allow prediction of the number of whales passing through the area on non-survey days, including those at the very beginning and end of the expected period of northward migration), and integrating the fit throughout the migration period, yields an estimate of absolute abundance of northward migrating whales.

\section{Modelling the aerial survey data to obtain relative density estimates}

Note that in what immediately follows, 'density' refers to 'relative density', since no account for perception nor availability bias has been made (i.e. in this section, $g(0)$ is assumed to be equal to one).

For each flight, pod density is estimated using a spatial generalised additive model (GAM) similar to the 'count model' of Hedley and Buckland (2004). The response variable of the model is the number of pod sightings per 'segment' of the transect, where the segment length must be specified but should be selected such that sighting conditions (and geographic location) do not change appreciably within a segment. An offset variable is included in the model to account for differences in estimated probabilities of detection 
within each segment, and consequential potentially different effective search areas of the segments. The offset is estimated using multiple covariate distance sampling - single platform line transect estimation but with the ability to include covariates (such as sea state) in the scale parameter of the detection function (Marques and Buckland, 2003).

With a logarithmic link function, the general form of a GAM of this type may be written:

$$
E\left[n_{i}\right]=\exp \left\{\log \left(2 l_{i} w \cdot \hat{p}_{i}\right)+\sum_{k} f_{k}\left(z_{i k}\right)\right\},
$$

where $\mathrm{E}\left[n_{i}\right]$ is the expected number of sighted pods in the $i^{\text {th }}$ segment (assumed to follow a Tweedie distribution); $l_{i}$ is the length of segment $i ; w$ is the perpendicular (right-) truncation distance; $\hat{p}_{i}$ is the estimated probability of detection of a pod in segment $i ; z_{i j}, j=1, \ldots k$ denotes the value of the $j^{\text {th }}$ (spatial) covariate in the $i^{\text {th }}$ segment; and the $f_{k}$ are (smooth) functions. Extending this form, it is feasible for a function $f$ to depend on more than one covariate (e.g. $f\left(\right.$ lat $_{i}$, lon $\left.\left._{i}\right)\right)$, and/or for the covariate to be temporal (e.g. Day).

Hedley and Buckland (2004) suggested that variance from a spatial model of this type may be estimated using an appropriate resampling scheme such as a non-parametric or parametric bootstrap. In practice, these bootstrapping techniques frequently give biased results when smoothing models. Wood (2006, p.246-7) proposed an alternative approach which can be much simpler to implement, and appears not to suffer from the bias often associated with the bootstrapping approaches. This approach uses a 'prediction matrix' to map the model parameters to the predictions of the linear predictor, in conjunction with simulation from the posterior distribution of the parameters. The analysis in this report uses Wood's (2006) approach, conditioning on the estimated smoothing parameters.

The offset in the model above includes an estimate $\hat{p}_{i}$, of the probability of detection. We propagate the uncertainty by explicitly accounting for variability in $\hat{p}_{i}$ in the spatial model (Williams et al., 2011).

\section{Estimating mean pod size}

Results from other studies have shown that aerial survey pod size estimates can be negatively biased, since the animals are in view only for a relatively short period of time. In contrast, some pods sighted from the land station could be tracked for over an hour, although such pods would tend to be those migrating closer inshore so may not necessarily be representative of all migrating pods.

In order to estimate mean pod size, we compared three methods: (a) the mean size of pods sighted from the landbased station within $12 \mathrm{~km}$; (b) the mean size of pods sighted within $0.7 \mathrm{~km}$ of the trackline from the aerial survey; and (c) truncating at $0.7 \mathrm{~km}$ as for method (b), a spatial model for estimated pod size was fitted to examine variation in pod size within the survey region. For method (a), $12 \mathrm{~km}$ was selected as a truncation point beyond which recorded pod sizes were considered less reliable. For methods (b) and (c), $0.7 \mathrm{~km}$ was selected as a truncation distance within which pod size did not affect detectability (i.e. to eliminate potential 'size bias' effects).

Estimating abundance from the land-based survey data Within the visible range of the land-based observers (here, up to $12 \mathrm{~km}$ offshore), the number of northward-migrating whales passing the land station per watch period (where a 'watch' is defined as a three hour period within a day, say) gives an estimate of their rate of passage. Using the doubleplatform data from the first survey week, logistic regression (Buckland et al., 2001; 1993) may be used to estimate the proportion of whale pods missed. Three correction factors for pods missed are estimated, depending on the mode of survey operation at the time (i.e. 'Car' Platform only, 'Bush' Platform only, or Double Platform). It is assumed that the probability of detection of a pod from one platform is independent of whether it is detected from the other, and independent of whether other pods are detected by either platform. Detection probability may be modelled as a function of covariates. The counts from each watch are then adjusted according to the mode of survey operation. Summing, and standardizing for different hours of effort, daily estimates of pod abundance may be calculated. The estimates correspond to the survey region in view from the land-based station only.

\section{RESULTS}

\section{Use of the aerial data}

Prior to analysis, transect line lengths were calculated from the GPS positional data using $R$ code adapted from Visual Basic Geofunc functions (J.L. Laake, National Marine Mammal Laboratory, USA). Corresponding formulae are given in Zwillinger (2002). Heading angles were corrected for aircraft drift angle, and perpendicular distances $(x)$ to sightings were calculated using the following simple tangent formula (e.g. Pike et al., 2008):

$$
x=h(\tan (90-\theta)) \sin (\varphi),
$$

where $h$ is altitude; $\theta$ is declination angle to the sighting; and $\varphi$ is drift-correcting heading angle.

During the aerial survey, the swimming direction of sighted pods was recorded where possible. Since the objective of the survey is to obtain estimates for the northward-migrating component of the population only, then the swimming direction is critical. Out of 855 pods with either a swimming direction recorded, or designated as 'milling', then 571 (67\%) of these were recorded as travelling northwards (where NE and NW were classified as North). In total, 1,357 humpback (including 'possible' humpback) pods were recorded whilst on effort and $42 \%$ of these were recorded as travelling northwards. As in Paxton et al. (2011), humpbacks with no direction recorded (and not milling), were randomly allocated a swimming direction according to the relative proportions of directions observed on a given flight. This increased the sample size considerably to 920 northward-migrating whales (seen on effort). Hereafter, we analyse the data for whales recorded as travelling north (NM whales) separately from a dataset of NM whales augmented by sightings with unknown swimming direction, but randomly allocated to be travelling northwards (NM+ whales).

\section{Detection function estimation: aerial data}

Two aircraft were used on the aerial survey: the Partenavia, fitted with bubble windows, and the Cessna, with flat windows. Angles of declination taken from each aircraft suggested that strips of about $80 \mathrm{~m}$ (40m either side of the trackline) and of about $260 \mathrm{~m}$ were obscured from the view of observers immediately beneath the Partenavia and the Cessna respectively. Histograms of perpendicular distances suggested that some pods were being missed beyond this strip for the Partenavia, perhaps because it was uncomfortable for the observers to look down at such an 
angle. The problem was alleviated by extending the lefttruncation distance to $260 \mathrm{~m}$ for both aircraft; thus about $6 \%$ of the sightings were excluded from further analysis (see Table 1).

Initial exploratory analyses of the NM aerial line transect data were conducted in Distance v5.0 (Thomas et al., 2010), and model selection for both NM and NM+ whales was based on these analyses. Potential factors or covariates included Cloud cover, Sightability, Side of Aircraft (Port/Starboard), Sea state, Wind speed, Observer, Pod size and Aircraft. The detection function was modelled as a function of perpendicular distance, and these variables were considered for inclusion via the scale parameter of this function (either a hazard-rate or a half-normal form). The perpendicular distance data were right-truncated at $3.0 \mathrm{~km}$ for NM whales and $4.5 \mathrm{~km}$ for $\mathrm{NM}+$ whales. A stepwise forward selection procedure (starting with a model containing perpendicular distance only) based on Bayes' Information Criterion (BIC) was used for model selection.

For both NM and NM+ pods, the model selected by BIC alone would have included Pod size. However the fitted detection function from such a model was such that estimated probability of detection decreased as pod size increased, counter to expectation. For NM+ pods, the BIC also suggested a model including Sightability was better than a perpendicular-distance-only model. Similarly to pod size, however, probability of detection was estimated to be lower in 'Excellent' conditions than in 'Good' and 'Poor' conditions. The other covariates were not found to significantly improve upon a perpendicular-distance-only fit, and so in the absence of an explanation for the relationship between Detectability and Pod size, or between Detectability and Sightability, half-normal models of perpendicular distance only were fitted to both the NM and the NM+data. Fitted detection functions are shown in Fig. 2. Estimated effective strip half-widths were $2.05 \mathrm{~km}( \pm 0.088)$ and $2.46 \mathrm{~km}( \pm 0.084)$ respectively.

\section{Mean pod size estimation}

Pods seen from the land-based survey ranged in size from 1-6 whales, with most groups sighted as singletons or pairs. During the Double Platform component of this survey, only about half of the pod sizes recorded was in agreement between the two platforms. Estimated mean pod size from the land-based survey varied from about $1.7( \pm 0.084)$ to 1.85 $( \pm 0.056)$, depending on the subset of data selected.

As for the land survey, most pods sighted from the air were of 1 or 2 whales; pod size ranged from $1-8$. No spatial or temporal trend in pod size was detected from the aerial data, and there was no evidence of 'size bias'. In fact, as noted above, any effect of pod size on detectability appeared to be in the 'wrong' direction. Mean pod size from the aerial data was estimated as $1.80( \pm 0.043)$ for NM whales. The point estimate for $\mathrm{NM}+$ whales was considerably lower at $1.64( \pm 0.032)$, but this is perhaps not surprising, since this dataset includes pods for which a swimming direction was not recorded, and presumably pod size would also be more

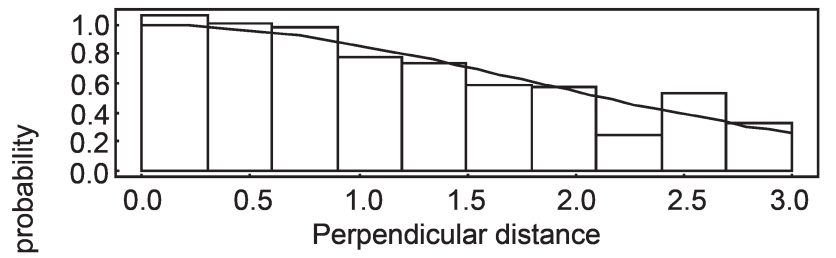

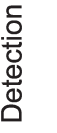

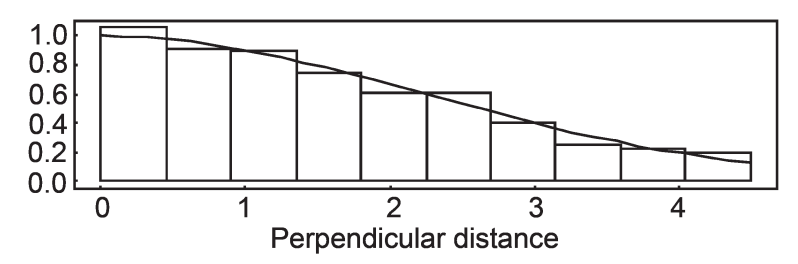

Fig. 2. Fitted detection functions (half-normal models) for aerial survey data. Perpendicular distances in $\mathrm{km}$. NM pods: top panel. NM+pods: bottom panel.

difficult to ascertain for such pods also (and would tend to be under-estimated). Note therefore, that in this analysis for both $\mathrm{NM}$ and $\mathrm{NM}+$ estimates, the mean pod size of 1.80 was considered most appropriate and used for all conversions from pod density to whale density.

\section{Land-based survey \\ Sighting survey}

Since sightings from the aerial survey extended far beyond the visible range of the land station, it was clear that an 'abundance' estimate from the land-based survey, even for the two weeks of its duration, would only represent a proportion of the migrating population. In this section, the estimate calculated corresponds to migrating animals passing within $12 \mathrm{~km}$ of the shore. To use this estimate for calibration of the aerial estimates below requires abundance to be estimated for a corresponding region from the aerial survey (see 'Calibration of aerial survey').

To estimate the number of pods missed within $12 \mathrm{~km}$ offshore during the land-survey, the double count data collected during the first week of that survey were fitted using logistic regression (Buckland et al., 2001; 1993). In order to obtain a reasonable sample size, the model was fitted to NM+ data. Potential covariates were Team, Distance offshore, Sea State, Glare width, Wind speed, and Pod size, and interactions of the latter variables with team. The final model was selected by AIC using a backwards stepwise algorithm. The number of pods seen by at least one land platform was 74; this was reduced to 49 after truncation at $12 \mathrm{~km}$. Covariates selected for the untruncated data were team and the interaction term 'Team:Distance offshore'. When the data were truncated at $12 \mathrm{~km}$ offshore, an additional interaction term 'Team:Pod size' was also selected. The number of pods seen on each watch period of the land survey was then adjusted according to the estimated correction factors (depending on which platform was operating) in Table 3. Since there was some daily variation in the number of hours of survey effort, the estimates were

Table 3

Estimated correction factors for numbers of pods missed from the land station.

\begin{tabular}{cccccccc}
\hline & Truncated at $12 \mathrm{~km}$ & & & \multicolumn{3}{c}{ Untruncated } \\
\cline { 1 - 2 } \cline { 5 - 7 } Missed by both & Missed by Car & Missed by Bush & & Missed by both & Missed by Car & Missed by Bush \\
\hline $1.032( \pm 0.026)$ & $1.150( \pm 0.029)$ & $1.297( \pm 0.033)$ & & $1.074( \pm 0.034)$ & $1.262( \pm 0.039)$ \\
\hline
\end{tabular}




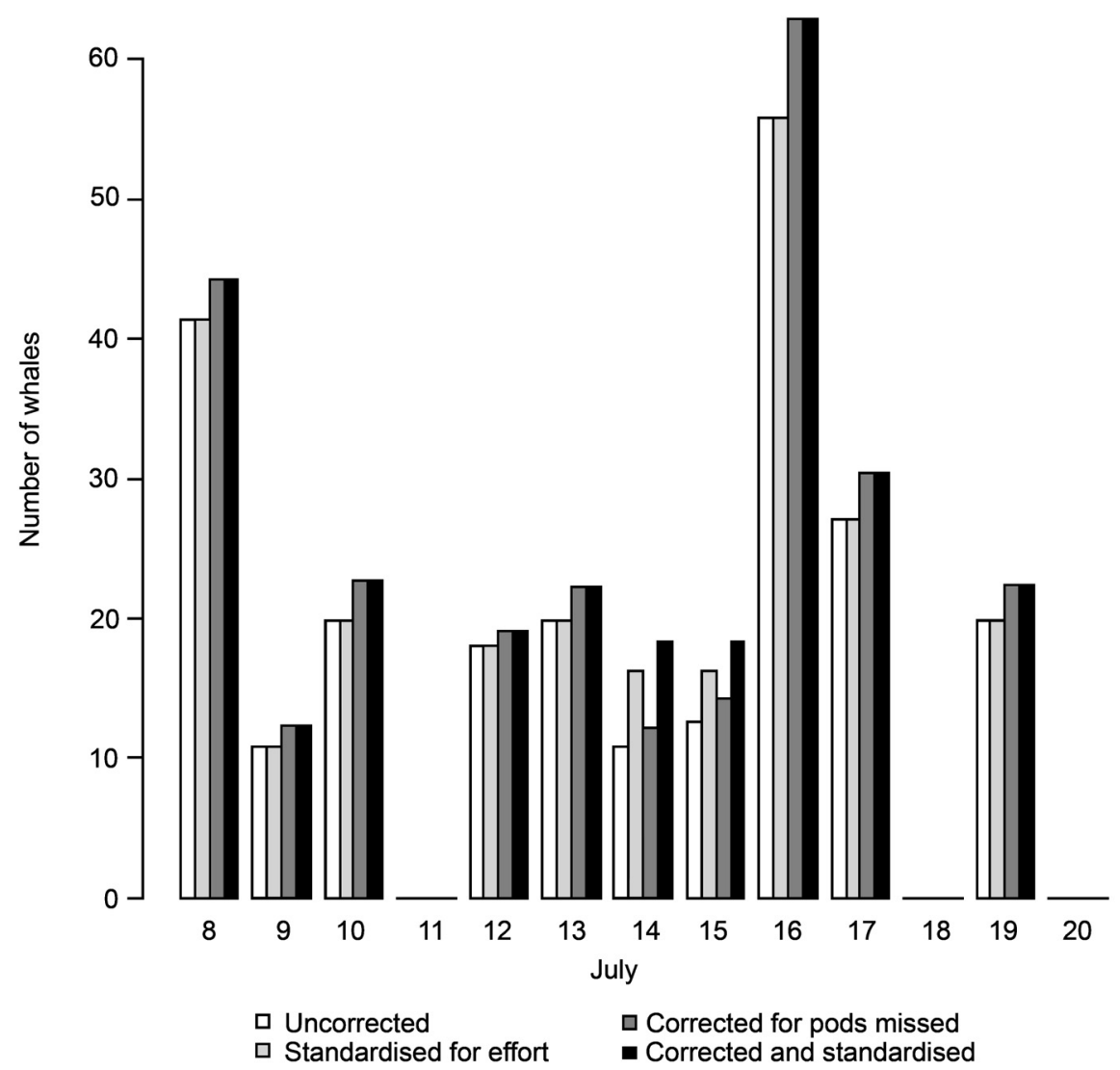

Fig. 3. Counts of number of whales passing the land station within $12 \mathrm{~km}$ of the shore. 'Uncorrected' estimates are the raw counts; 'standardized for effort' adjusts the estimates to correspond to 9 hours of effort; 'corrected for pods missed' uses the correction factors in Table 3 (truncated at $12 \mathrm{~km}$ ) to adjust the counts.

also standardised by effort. Using a mean pod size estimate of 1.80, estimates for NM whales corrected and standardised to 9 hours per day are shown in Fig. 3. Data from 18th July, on which day there were 2.5 hours of effort, were excluded from the analysis. The total estimated number of pods was 154 (totalling 276 whales).

\section{Focal follows}

A total of 17 focal follows was carried out in week 2 (this small sample size was due to the amount of down time due to poor weather conditions). An additional 5 pods were focally followed in week 1 , when the emphasis for two team effort was on obtaining double-platform count data. Pod compositions were 3 singletons, 11 pairs, 3 mother and calf groups, and one of each of a group of 3,4 , and 5 adults. The data are summarised in Table 4. As there was only a total of 22 focally followed pods, speed of travel, surfacing time and dive time were calculated averaging across all pod compositions. This assumption seemed quite reasonable for speed and dive time calculations; more variation across pod composition was evident in time spent at the surface (which includes time spent 'shallow diving', but for which it is considered that whales would still be visible from the air). The average speed of travel was calculated as $5.56 \mathrm{~km} / \mathrm{h}$ $( \pm 0.31)$; the mean proportion of time spent underwater was 0.43 and at the surface 0.57 .

\section{Spatio-temporal model of the aerial data}

Transects covered on effort were divided into segments of length approximately equal to $10 \mathrm{~nm}(18.5 \mathrm{~km})$, and the number of pods sighted in each segment was calculated. For each segment, an offset variable was computed as the logarithm of the effective area of the segment, where the effective area is given by twice the segment length multiplied by the estimated effective strip half-width from the detection function estimation described above. Potential spatial covariates were Latitude; Longitude and Bottom depth sourced from a $1^{\prime}$ by $1^{\prime}$ grid from the US National Geophysical Data Center, NOAA Satellite and Information Service (www.ngdc.noaa.gov/mgg/bathymetry). In addition, Day or alternatively, Week (where Day 1 - and the first day of Week 1 - was defined to correspond to 2 June, the assumed start of the whales' northward migration period) were potential temporal covariates.

Model fitting and model selection were conducted in the mgcv package (Wood, 2008) available in $\mathrm{R}^{1}$. A number of forms for the smoothing components of the spatial models were considered, but none of these showed evidence for including Bottom depth in the model. Level of smoothing was determined by restricted maximum likelihood (REML); the final selected model was a tensor product smooth (Wood, 2006) of a two-dimensional thin-plate spline of Latitude and Longitude, and a thin-plate spline of 'Day'.

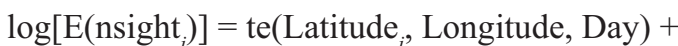

$$
\begin{aligned}
& \log \left(\text { estimated effective } \text { area }_{i}\right)+\mathrm{X}
\end{aligned}
$$

where $E\left(\right.$ nsight $\left._{i}\right)$ was assumed to follow a Tweedie distribution, with index parameter $=1.1$; and te is a tensor

${ }^{1} R$ Development Core Team. 2008. $R$ : a language and environment for statistical computing. R Foundation for Statistical Computing, Vienna, Austria. ISBN: 3-900051-07-0 http://www.R-project.org. 
Table 4

Summary of the raw focal follow data. Times are given as min:sec; rates are given per minute per whale.

\begin{tabular}{lccccccc}
\hline $\begin{array}{l}\text { Pod } \\
\text { composition }\end{array}$ & $\begin{array}{c}\text { Number } \\
\text { of pods }\end{array}$ & $\begin{array}{c}\text { Mean down } \\
\text { time }\end{array}$ & $\begin{array}{c}\text { Mean surface } \\
\text { interval }\end{array}$ & $\begin{array}{c}\text { Mean } \\
\text { blow rate }\end{array}$ & $\begin{array}{c}\text { Mean } \\
\text { breach rate }\end{array}$ & $\begin{array}{c}\text { Mean surface- } \\
\text { active rate }\end{array}$ & $\begin{array}{c}\text { Mean speed } \\
(\mathrm{km} / \mathrm{h})\end{array}$ \\
\hline Singleton & 3 & $03: 23$ & $09: 04$ & 3.11 & 0.189 & 0.313 & 3.96 \\
Pair & 11 & $04: 31$ & $04: 52$ & 2.14 & 0.062 & 0.122 & 5.74 \\
Cow+calf & 3 & $03: 25$ & $07: 52$ & 1.58 & 0.093 & 0.170 & 4.75 \\
Multiple adult & 5 & $04: 02$ & $08: 47$ & 1.95 & 0.036 & 0.117 & 6.63 \\
Mean & - & $04: 06$ & $06: 45$ & 2.11 & 0.073 & 0.147 & 5.56 \\
SD & - & $01: 23$ & $04: 37$ & 0.85 & 0.112 & 0.166 & 1.47 \\
\hline
\end{tabular}

product of thin-plate spline smooths of Latitude and Longitude, and Day. The offset variable for the $\mathrm{i}^{\text {th }}$ observation, $\log$ (estimated effective area $a_{i}$, was estimated using the effective strip widths estimated from the distance sampling analysis. $\mathrm{X}_{\mathrm{i}}$ is a vector of first derivatives and was used to propagate variance, penalized according to the Hessian of the respective detection function fit (Williams et al., 2011). Estimation of tail densities (before the first flight of the season and after the last) was improved by adding two zero counts to the data, one on 2 June and one on 7 September.

Integrating across the predicted density surfaces for each day within the assumed migration period gave snapshot estimates of abundance. To convert these estimates into daily estimates, the rate of passage through the survey area was estimated using an average speed of travel of travel of $5.56 \mathrm{kmh}^{-1}$. The latitudinal width of the survey area was $86.7 \mathrm{~km}$, hence the snapshot estimates were multiplied by a correction factor equal to $(5.56 \times 24) / 86.7$ to convert them to daily estimates. (Estimated variance in speed of travel was not incorporated in the variance of the final abundance estimates.) Multiplying by the estimated mean pod size resulted in daily estimates of whale abundance, uncorrected for availability and detection bias (Fig. 4). Total relative abundance was $10,840(8,640-16,860)$ for NM whales and $13,310(11,010-18,840)$ for NM+ whales (Table 5).

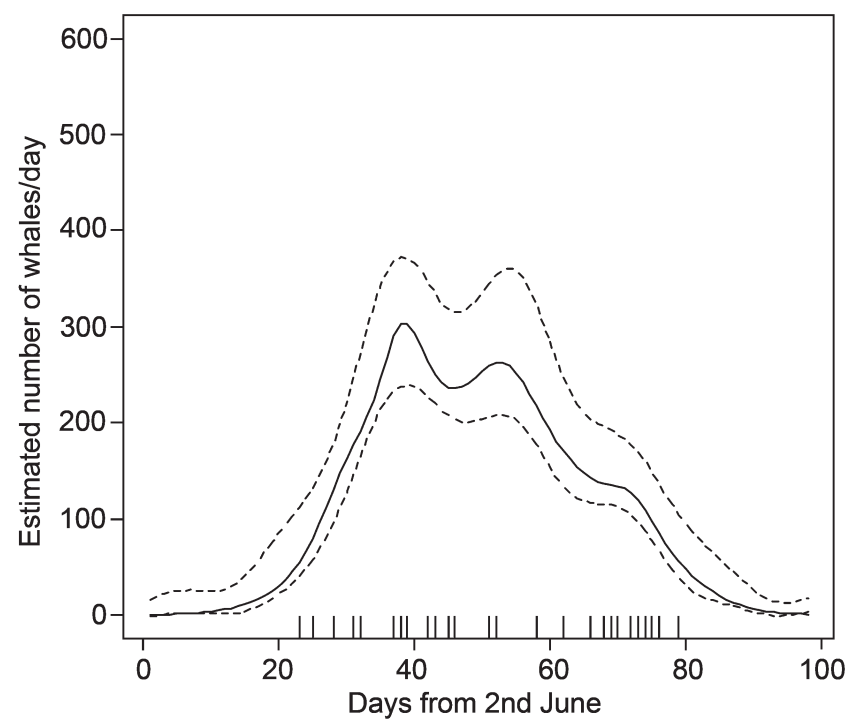

Fig. 4. Estimated whale abundance throughout the migration period from spatial modelling of aerial survey data. Dashed lines shows $95 \%$ percentile intervals obtained by simulating from the posterior distribution of the parameters of the fitted model. The intervals shown include variance in mean school size, but not in whales' migration speed. Rug plot (long ticks) along the $\mathrm{x}$-axis shows days during this period on which flights were completed.
For illustrative purposes, a similar model with Week instead of Day was also fitted, yielding the plots shown in Fig. 5. These demonstrate how the distribution of whale pods varied during the course of the migration period. At the latitude of Cape Inscription, the estimated pod density as a function of distance offshore (averaged over flights during the two weeks of the land-based survey - i.e. weeks 7 and 8 ) is shown in Fig. 6. These plots indicate that density in week 7 increased gradually with distance offshore to a peak at around $30-35 \mathrm{~km}$ offshore. During week 8, peak density was over a larger distance, at around $20-35 \mathrm{~km}$ offshore. In both weeks, estimated density was very low beyond about $60 \mathrm{~km}$ offshore. Within the region of the land-based station (lower panels of Fig. 6), the increase in density with distance offshore was slightly greater (and slightly more pronounced) during the second week.

\section{Calibration of the aerial survey}

From the land-based survey, we have two sets of estimates of pod abundance: $\hat{N}_{9 L_{1}}, \hat{N}_{9 L_{2}}, \ldots \hat{N}_{9 L_{10}}$ for NM and for NM+ pods. (The subscript ' 9 ' denotes for the 9 hour period of a standard survey day; $L$ denotes 'land-based survey' and these are for the 10 days for which there was at least 6 hours of survey effort.) Notwithstanding the difficulties in recording data from the land owing to the distances offshore at which many of the whales migrated, these estimates only correspond to the visible land-based survey region (here, assumed to be about $12 \mathrm{~km}$ offshore).

From the aerial survey, we again have two sets of estimates of pod abundance, one set for NM pods and one for $\mathrm{NM}+$ pods. These snapshot estimates are available not only for the days on which flights were flown, but by predicting from the spatio-temporal model above, also for any day within the assumed migration period. In order to use the land-based estimates for calibration of the aerial estimates, the calibration must correspond to the same survey region and over the same time period.

Since only about $15 \%$ of pods passed within the visible land-based survey region, the calibration approach adopted here is as follows:

(1) estimate 'snapshot' abundance for the seven 1' by 1' gridsquares at the latitude of Cape Inscription, for the corresponding ten days of the land-based survey;

(2) convert these to 9 hour estimates (using the estimate of speed of travel of $5.56 \mathrm{~km} / \mathrm{h}$ and a latitudinal width of $1.856 \mathrm{~km})$

(3) fit a linear regression model (with no intercept) to estimate the slope of the regression of aerial estimates against land estimates; the slope is the calibration factor.

As would be expected, the calibration factor estimate varied substantially according to which subset of data was used for the calibration. We considered NM and NM+ pods 

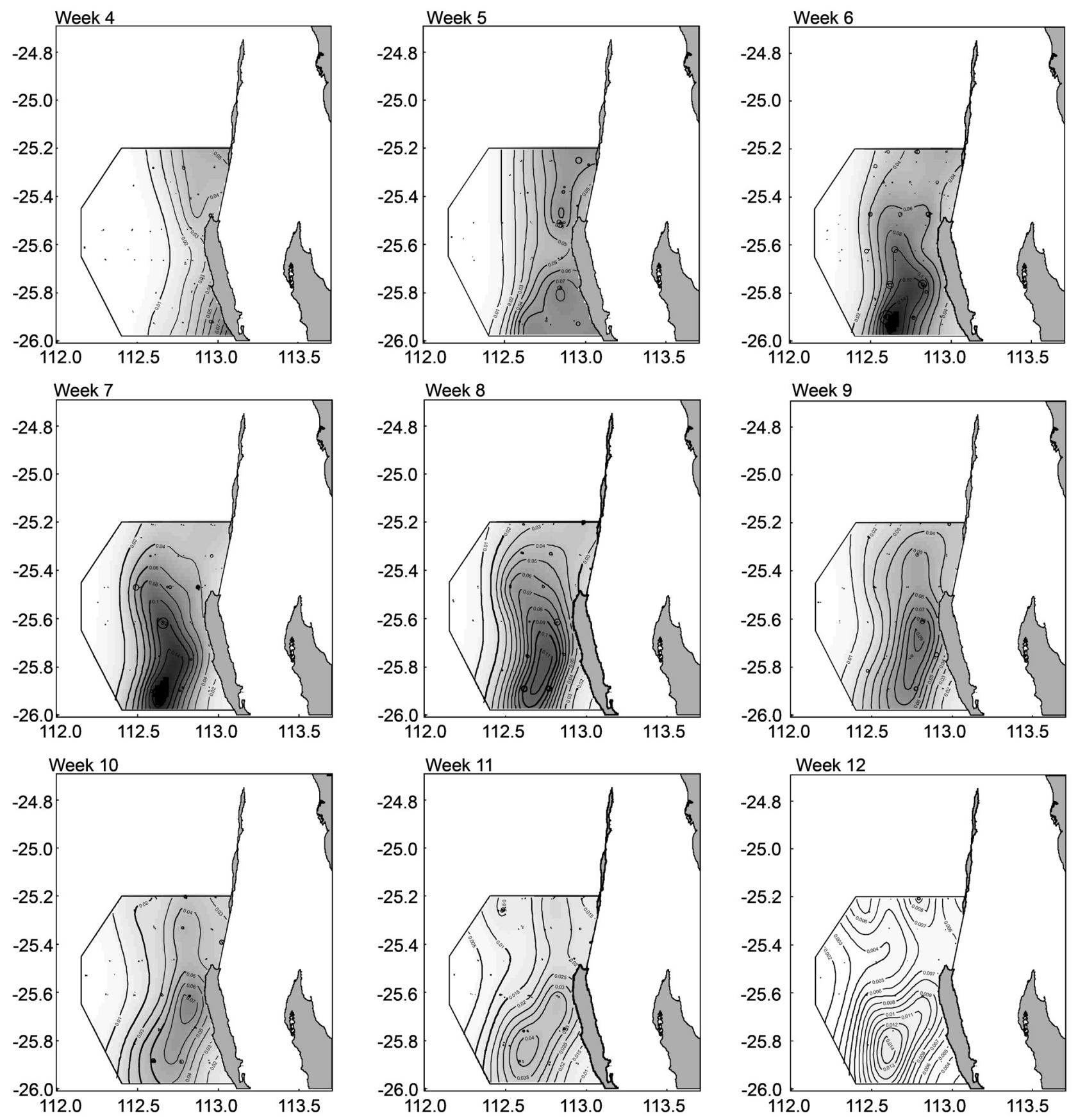

Fig. 5. Estimated spatial variation in NM pod density throughout the northward migration season, estimated from the aerial survey data. Weeks 1-3 and 1314, all of which had relatively low densities, not presented here. Circles/dots represent 'data', i.e. weeks with at least one flight conducted (circles represent a segment with at least one sighting; dots represent no sightings in a segment). Week 2 corresponds to the w/c 9 June 2008 . Week 12 corresponds to the w/c 18 August 2008.

separately, but took no account of possible differences in recording direction of travel between the two surveys. Because of the large number of land-based sightings that had no offshore distance recorded, a set of results was generated which included land-based sightings with offshore distances within $12 \mathrm{~km}$ plus sightings with a missing offshore distance. This set of results gave an indication of the sensitivity of the results to the dataset used. The estimated total number of pods from the land-based survey increased by about 70 $75 \%$; the calibration factor went down by about $40-50 \%$. The estimated calibration factors $(\hat{g}(0) \mathrm{s})$ are shown in Table 5 ; applying these factors gives total whale abundance ranging from $17,810(14,210-27,720)$ to $36,600(30,520-$ $52,250)$.

\section{DISCUSSION}

The estimates presented in Table 5 are very different, significantly so for the two rows of data which represent different subsets of the land-based data. The land survey was not particularly successful in providing a suitable 'calibration' for the aerial survey estimates, i.e. one that accounted for bias due to a lack of availability of diving pods and due to pods at the surface being missed. This is primarily due to the high proportion of animals that were beyond the range of the land-based observers, and so the overlap between the aerial survey - already for only a few days was also spatially limited. Additionally, there may be some issues related to the different relative abilities of the aerial 

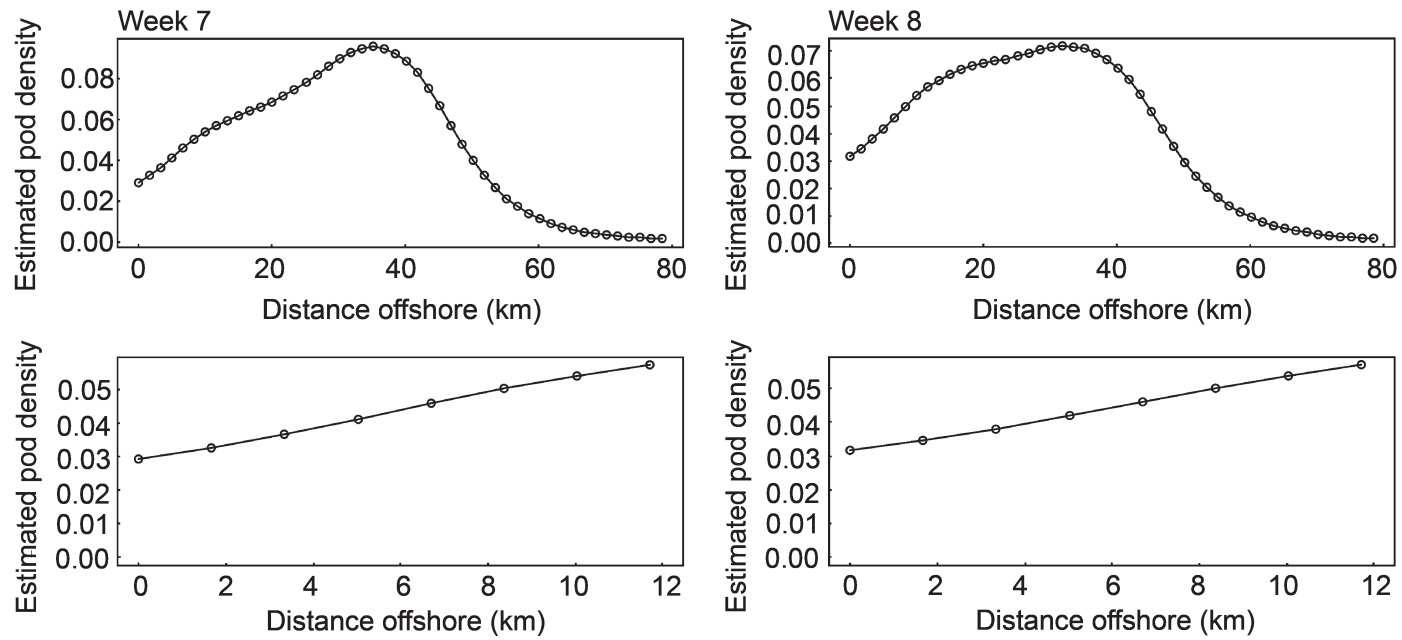

Fig. 6. Estimated pod density as a function of distance offshore (from Cape Inscription). Left panels for week 7 (w/c 8 July 2008 ); right panels for week 8 (w/c 15 July 2008). Upper panels show the estimated density from the shore to the western edge of the survey area; lower panels give this for the first $12 \mathrm{~km}$ offshore only.

and land-based survey to identify the direction of a sighted pod. During the land-based survey, for pods sighted sufficiently closely for tracking purposes, recording direction was straightforward whereas for the aerial survey, determination of swimming direction was generally based on fewer cues over much shorter periods of time in view.

The primary objective of the 2008 survey was to obtain an estimate of absolute abundance of northward-migrating whales. Whilst we can be reasonably confident about the relative estimates presented in Table 5, there is wide variation in the absolute estimates as a result of substantially different estimates of $g(0)$. A priori, from previous analyses and studies elsewhere, estimates in the range $0.3-0.4$ or so might have been expected, with such an estimate correcting for both availability and perception biases. It is therefore necessary to investigate further the reasons for the evidently much higher $\hat{g}(0)$ values reported here. The estimation method used by Paxton et al. (2011) estimated an 'availability curve' indicating the true (relative) density of pods with distance from shore. Within the region of the landbased observers, this showed a steady increase in density with distance offshore, up to a peak at around $10 \mathrm{~km}$. The detection function fitted to the distances offshore (using the land-based data) showed a very steady decrease in detectability with distance, based on a half-normal detection function. Differences between the two curves were used to correct the counts from the land-survey for pods missed from the land, and then $g(0)$ was estimated by comparing the aerial abundance in the region with the land-based abundance, over the two-week period of the land-survey in 2005. The correction factor applied to the land data for each day was about 1.5 (C.G.M. Paxton, pers. comm.) The data for the 2008 survey were markedly different from those obtained in 2005. Furthermore, they were very different even between the two weeks of the land survey duration (Fig. 7). The improvement to the design of the 2008 survey meant that the estimated number of pods missed from the land was able to be estimated from the double-platform effort during the first week of that survey, yielding correction factors by platform operation (see Table 3 ). The number of pods on which these calculations were based was 73 if the data were not truncated; it decreased to only 48 if the data were truncated at $12 \mathrm{~km}$. The estimates of Table 3 appear reasonably plausible compared with other studies of migrating populations, but if anything perhaps a little lower than might be expected, especially given the distances offshore at which the whales passed. If the estimates of Table 3 are in fact negatively biased, then the estimates of $g(0)$ would be lower (and abundance consequentially higher). Aside from the problems of the offshore distribution of the whales in 2008, the double-platform land-based approach to estimate the number of pods offshore would be preferable to the aerialland calibration, since the data would be expected to be more reliable.

An alternative approach based directly on surface availability of pods (Barlow et al., 1988) to estimate a $g(0)$ correction for availability bias was implemented in Bannister and Hedley (2001) in their analysis of the 1999 survey data:

$$
P(\text { being visible })=(s+t) /(s+d)
$$

where $s$ is the average time a whale stays at the surface; $d$ is the average time spent below the surface (i.e. 'deep-diving'),

Table 5

Estimates of abundance for NM and NM+ whales. The large difference between rows depends on what portion of the land data are used in the calibration of the aerial survey estimates. 'Relative' estimates are uncorrected estimates from the aerial survey; 'absolute' estimates are those corrected by ' $g(0)$ ' estimates from the land-aerial calibration. Numbers in parentheses are $95 \%$ percentile intervals; these do not include variance in $\hat{g}(0)$.

\begin{tabular}{|c|c|c|c|c|c|c|}
\hline \multirow[b]{2}{*}{ Land data, truncated at $12 \mathrm{~km}$} & \multicolumn{3}{|c|}{ NM whales } & \multicolumn{3}{|c|}{$\mathrm{NM}+$ whales } \\
\hline & Relative & $\hat{g}(0)$ & Absolute & Relative & $\hat{g}(0)$ & Absolute \\
\hline Missing distances excluded & 10,840 & 0.61 & $\begin{array}{c}17,810 \\
(14,210-27,720)\end{array}$ & 13,310 & 0.59 & $\begin{array}{c}23,060 \\
(19,060-32,640)\end{array}$ \\
\hline Missing distances included & $(8,640-16,860)$ & 0.32 & $\begin{array}{c}34,290 \\
(27,340-53,350)\end{array}$ & $(11,010-18,840)$ & 0.36 & $\begin{array}{c}36,920 \\
(30,520-52,250)\end{array}$ \\
\hline
\end{tabular}


Week: 1 Car: truncated at $12,000 \mathrm{~m}$

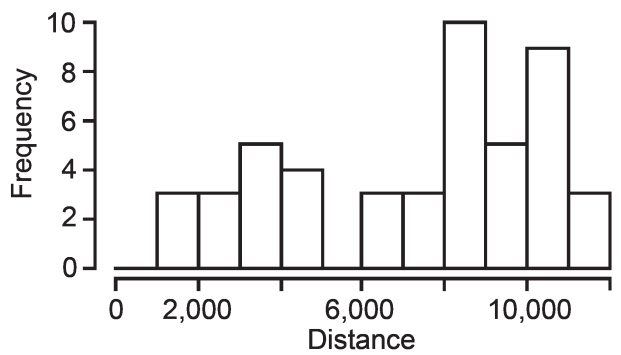

Week: 1 All: truncated at $12,000 \mathrm{~m}$

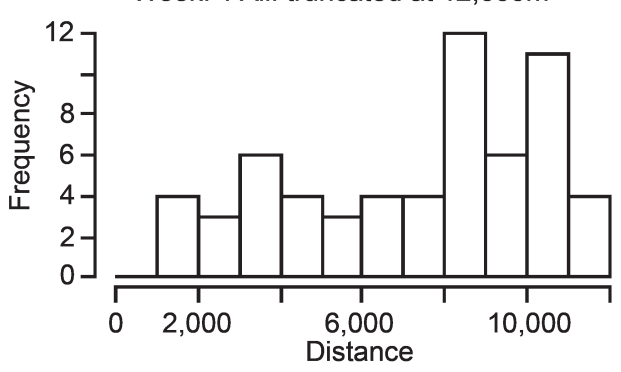

Week: 2 Car: truncated at $12,000 \mathrm{~m}$

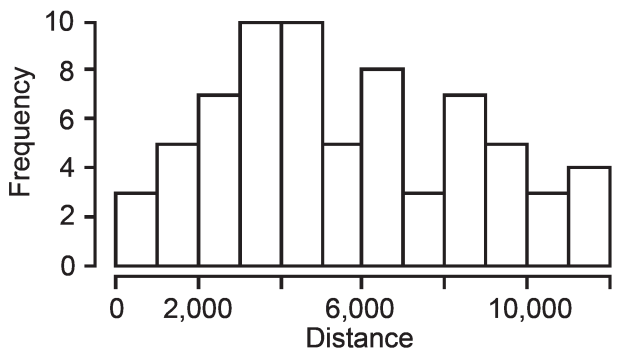

Week: 1 Bush: truncated at 12,000m
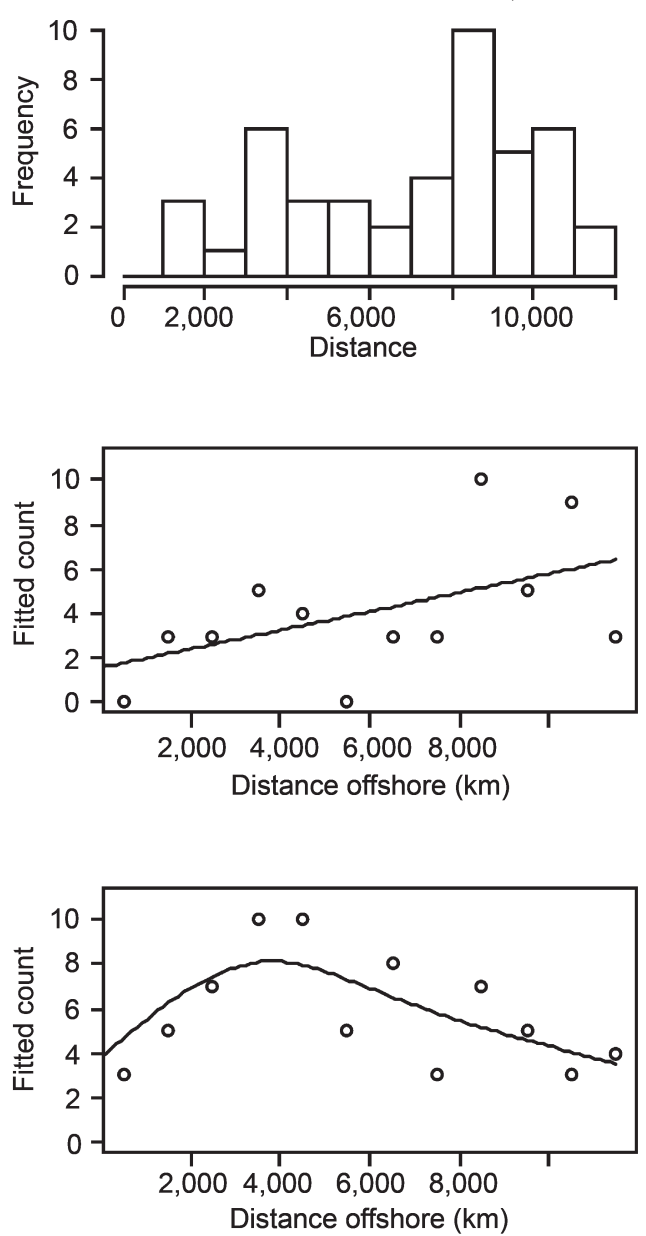

Fig. 7. Distribution of NM humpback whale pods with distance offshore, by platform and by week. Data have been truncated at $12 \mathrm{~km}$. (During the second week, only the 'Car' platform operated). Fitted curves are penalized regression splines with smoothing parameters selected by generalized cross validation (Wood, 2006; p130-133).

and $t$ is the window of time during which an animal is within the visual range of an observer. A range of estimates for the values of $s$ and $d$ were made based mainly on observational data from experienced humpback whale scientists familiar with 'Australian' whales. A histogram of forward and aft distances was used to gain an idea of the time window, $t$. Ignoring the fact that two aircraft with rather different fields of view were employed on the 2008 survey, a similar histogram of distances to sighted pods is given in Fig. 8. This suggests that a maximum sighting 'window' can be estimated as about $8.5 \mathrm{~km}$, comprising animals seen ahead (generally up to $5.0 \mathrm{~km}$ ), abeam, and aft (up to $3.5 \mathrm{~km}$ ). These data suggest a rectangular sighting window of about $4.5 \mathrm{~km}$ (estimated from a half-normal model). The focal follow data collected during the 2008 land-based survey were used to provide estimates of $s$ and $d$ of 405s and 246s (see Table 4). Average speed during the aerial survey was $132 \mathrm{knots}$ $(244 \mathrm{~km} / \mathrm{h})$. An estimate of $t$ for a window of $4.5 \mathrm{~km}$ is $66 \mathrm{~s}$, giving an estimate of $g(0)$ of 0.72 - again, much higher than from previous analyses. Estimates from this approach are fairly insensitive to quite large changes in window-width (for example values of $g(0)$ of 0.68 and 0.81 result from windows of $2.5 \mathrm{~km}$ and $8.5 \mathrm{~km})$. The estimate of 0.72 is higher than those in the upper row of Table $5(0.61$ and 0.59$)$-i.e. those computed when sightings from the land-based survey with no offshore distance recorded were excluded. The former does not account for perception bias, however, so it would be expected to be higher than estimates from the combined survey approach which do.

The $g(0)$ estimates in the bottom half of Table 5 are some 40-50\% lower than those in the upper half, but are more in line with our a priori expectation. These estimates are derived from land-based estimates which included sightings for which no offshore distance was recorded. This would most certainly mean that 'too many' pods were included in the land counts, especially since one of the main reasons for a missing offshore distance was difficulty in acquiring two theodolite fixes of the same pod. Even beyond 8km, whales were sighted on the horizon. Therefore at least some of the pods with missing distances would be expected to be within $12 \mathrm{~km}$ offshore.

A second objective of the 2008 survey was to compare results with the 1999 and 2005 surveys. Previous analyses had estimated relative abundance of whales over a similar migration period to that assumed here as 3,441 for 1999 (Bannister and Hedley, 2001) and about 22,500 $\times 0.268=$ 6,030 for 2005 (Paxton et al., 2011; Table 2, results set 13) - an estimated increase rate of $9.8 \%$ per annum. The estimate of 10,840 presented here would represent an implausible rate of increase of $13.6 \%$ from the 1999 estimate; this rate is even more implausible were it based on only the 2005 estimate. Paxton et al. (2011) retrospectively applied a correction from their paper to the 1999 estimate to estimate absolute abundance of northward-migrating humpback whales as 


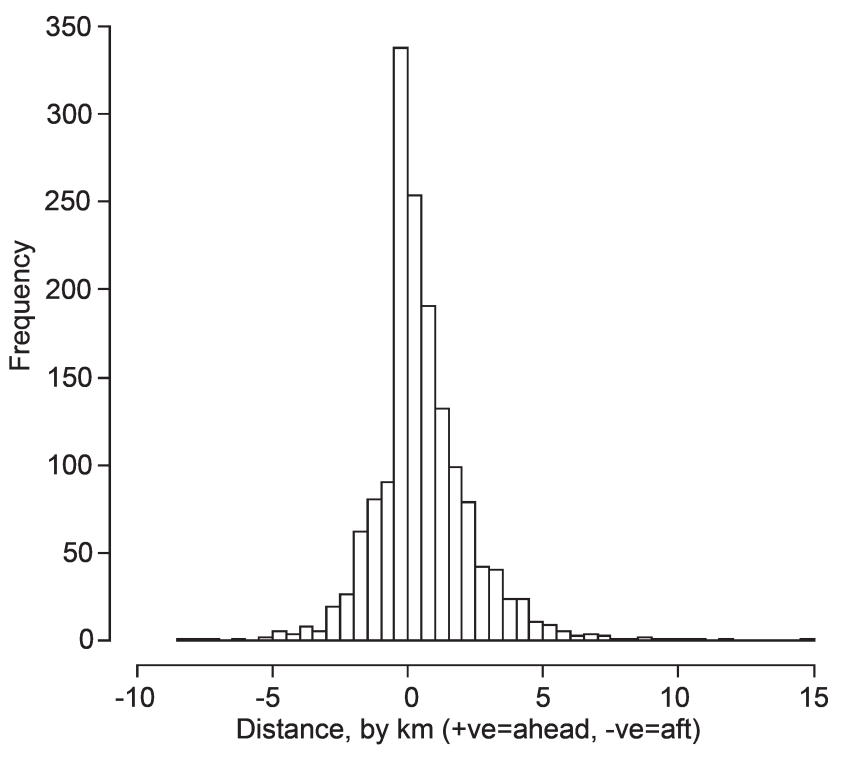

Fig. 8. Fore, abeam and aft distances from the aerial survey data.

11,500 (95\% CI 9,200-14,300) which fell within the range of 8,207-13,640 broadly estimated by Bannister and Hedley (2001) . This compares with 22,500 (10,000-72,200) from the 2005 survey. (Note: The estimate of 22,500 was not considered the 'best' estimate of abundance by Paxton et al. (2011) since they considered that extrapolation beyond the last flight of the aerial survey was unreliable due to a presumed 'second pulse' in the migration curve. It is used in the comparisons here as the estimate which best corresponds temporally to the 1999 and 2008 migration periods.) The corresponding estimates from the present analysis are 17,810 $(14,210-27,720)$ or $34,290(27,340-53,350)$. The latter represents an estimated rate of increase of about $12.9 \%(\mathrm{CV}$ $=0.20)$ given an estimate of 11,500 in 1999 , or about $15.1 \%$ $(\mathrm{CV}=0.53)$ given an estimate of 22,500 in 2005. Given the conclusions of the Hobart Workshop on the Comprehensive Assessment of Southern Hemisphere Humpback Whales (IWC, 2011) that a rate of increase of $12.6 \%$ was biologically implausible, these estimated rates of increase are questionable. It is our belief, however, that the analysis in this paper is sufficiently robust that the point estimates of abundance obtained for the 2008 survey are reasonable. Clearly an infeasibly high rate of increase can result from initial abundance estimates being too low, as well as current estimates being too high.

Separate from the $g(0)$ estimation issue, is the question of the robustness of the estimates obtained from spatial modelling of the aerial survey data. Therefore, as a sensitivity test to the spatial modelling approach adopted for analysing these data, we compared the spatial modelling estimates (uncorrected for rate of passage and for $g(0)$ ) to those from a conventional line transect analysis in Distance (Thomas et al., 2010). Data used in the spatial modelling included all on-effort data; only data from the main E-W transects were used in the design-based line transect analysis as was done previously (Bannister and Hedley, 2001; Paxton et al., 2011; results sets 5 and 6). The results are shown in Fig. 9. It can be seen that the estimates from the spatial model are quite comparable to those from a standard line transect analysis, the main difference being that variation in encounter rate has been 'smoothed' out, as would be expected. Thus, there is no suggestion of anything untoward in the relative estimates presented in Table 5.

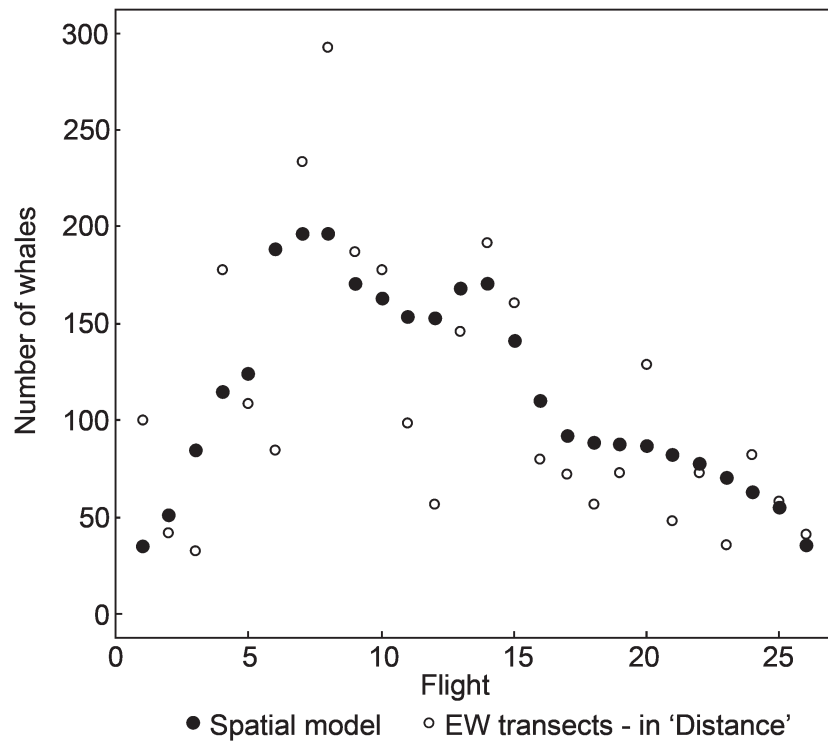

Fig. 9. Point estimates of abundance of humpback whales from each flight. Estimates from E-W transects are from a conventional line transect analysis in Distance; spatial model estimates are from the spatial model fitted in this report.

In conclusion, we propose that the best estimate for NM whales from the 2008 survey is $34,290(27,340-53,350)$. The caveat to this that some of the land-based sightings from which the estimate of $g(0)$ was derived would have been beyond the truncation distance of $12 \mathrm{~km}$ offshore, so the analysis is not strictly consistent. However, a $\hat{g}(0)$ of 0.33 is perhaps rather more plausible than the alternative of 0.63 when those sightings were excluded. On the other hand, the higher $\hat{g}(0)$ is compatible with the estimate obtained by directly estimating surface availability (Barlow et al., 1988). Since focal follow data were collected on this survey to estimate surfacing and diving times directly, there appears to be no obvious reason to discount these higher estimates, other than they are much higher than those obtained on previous aerial surveys. Therefore, we would also advocate a conservative estimate of $17,810(14,210-27,720)$ for this population, until these issues have been resolved.

A similar argument applies for the estimates of NM+ whales (Table 5). When a proportion of unknown-direction pods are included in the analysis, the abundance estimates increase (by about $23 \%$ in the case of relative abundance) compared to the corresponding NM estimates. These estimates are presented here as a sensitivity to the main NM analysis, for which comparisons across the three surveys are currently more reliable.

\section{ACKNOWLEDGEMENTS}

The authors gratefully acknowledge the financial support for this project from the Government of Australia, through the Australian Marine Mammal Centre, Tasmania. The collection of the survey data was a huge effort and thanks are due to the land-based survey volunteers (Josh Smith, Wendy Blanchard, Sarah Gardner, Christy Harrington, Sarah Jossul, Julianne Kucheran, and Melinda Rekhdahl) who endured very basic and trying conditions camping out on Dirk Hartog Island. Special appreciation is due to Verity Steptoe (who co-ordinated much of the aerial survey), for dealing promptly with data queries and questions about the aerial survey component, and to the other aerial observers, 
including Chris Burton and Kerry Jane Simons. Considerable logistical and other assistance, including transport and loan of equipment, was provided by the Department of Environment and Conservation, Denham - Shark Bay District Manager, Brett Fitzgerald, and Marine Ranger, Wayne Moroney. As for the 2005 survey, Dr Michael Noad, School of Veterinary Sciences, University of Queensland, helped most generously with the loan of equipment and advice. Facilities and administrative and other assistance continued to be provided to JLB at the Western Australian Museum through the courtesy of the Trustees, the Executive Director, and the Head, Science and Culture. Charles Paxton kindly provided the $R$-project he used for the 2005 analysis, which assisted in comparisons between the two surveys. The method used to propagate variance was suggested by Mark Bravington, who also wrote code to get this to run correctly within mgcv-gam. The paper was much improved following comments and suggestions from two anonymous reviewers.

\section{REFERENCES}

Bannister, J.L. 1964. Australian whaling 1963. Catch results and research. Aust. CSIRO Div. Fish. Oceanogr. Rep. 38: 1-13. plus 7 tables and 4 figs.

Bannister, J.L. 1995. Report on aerial survey and photoidentification of humpback whales off Western Australia, 1994. 17pp. [Unpublished report to the Australian Nature Conservation Agency (Environment Australia, Canberra)]

Bannister, J.L. and Hedley, S.L. 2001. Southern Hemisphere group IV humpback whales: their status from recent aerial survey. Mem. Queensl. Mus. 47(2): 587-98.

Bannister, J.L., Kirkwood, G.P. and Wayte, S.E. 1991. Increase in humpback whales off western Australia. Rep. int. Whal. Commn 41: 461-65.

Barlow, J., Oliver, C.W., Jackson, T.D. and Taylor, B.L. 1988. Harbor porpoise, Phocoena phocoena, abundance estimation for California, Oregon, and Washington: II. Aerial surveys. Fish. Bull. 86(3): 433-44.
Buckland, S.T., Breiwick, J.M., Cattanach, K.L. and Laake, J.L. 1993. Estimated population size of the California gray whale. Mar. Mammal Sci. 9(3): 235-49.

Buckland, S.T., Anderson, D.R., Burnham, K.P., Laake, J.L., Borchers, D.L. and Thomas, L. 2001. Introduction to Distance Sampling: Estimating Abundance of Biological Populations. Oxford University Press, Oxford, UK. vi $+x v+432 p p$.

Hedley, S. and Buckland, S.T. 2004. Spatial models for line transect sampling. J. Agric. Bio. Env. Stat. 9: 181-99.

International Whaling Commission. 2011. Report of the Workshop on the Comprehensive Assessment of Southern Hemisphere humpback whales, 4-7 April 2006, Hobart, Tasmania. Journal of Cetacean Research and Management (special issue 3): 1-50.

Marques, F.F. and Buckland, S.T. 2003. Incorporating covariates into standard line transect analyses. Biometrics 59: 924-35.

Marsh, H. and Sinclair, D.F. 1989. Correcting for visibility bias in strip transect aerial surveys for aquatic fauna. J. Wildl. Manage. 53(4): 1017-24.

Paxton, C.G.M., Hedley, S.L. and Bannister, J.L. 2011. Group IV humpback whales: their status from aerial and land-based surveys off Western Australia, 2005. Journal of Cetacean Research and Management (special issue 3): 223-234.

Pike, D.G., Gunnlaugsson, T. and Víkingsson, G.A. 2008. T-NASS Icelandic aerial survey: survey report and a preliminary abundance estimate for minke whales. 29pp. Paper SC/60/PFI12 presented to the IWC Scientific Committee, June 2008, Santiago, Chile (unpublished). 29pp. [Paper available from the Office of this Journal].

Thomas, L., Buckland, S.T., Rexstad, E.A., Laake, J.L., Strindberg, S., Hedley, S.L., Bishop, J.R.B., Marques, T.A. and Burnham, K.P. 2010 Distance software design and analysis of distance sampling surveys for estimating population size. J. Appl. Ecol. 47: 5-14.

Williams, R., Hedley, S., Branch, T.A., Bravington, M., Zerbini, A.N. and Findlay, K. 2011. Case study of a blue whale population to illustrate methods to estimate abundance and evaluate conservation status of rare species. Conserv. Biol. 25: 526-35.

Wood, S.N. 2006. Generalized Additive Models: an introduction with R. Chapman and Hall, Boca Raton, Florida. 391pp.

Wood, S.N. 2008. Fast stable direct fitting and smoothness selection for generalised additive models. J.R. Statist. Soc. B70(3): 495-518.

Zwillinger, D. 2002. Standard Mathematical Tables and Formulae. 31st ed. CRC, Bota Raton. 